\title{
C-reactive protein for the prediction of cardiovascular risk: Ready for prime-time?
}

\section{Daniel G. Hackam, Steven L. Shumak}

$\longrightarrow$ -reactive protein (CRP) is an acute phase reactant that increases during the host response to tissue injury, including that caused by infection, trauma, malignant disease and chronic inflammatory conditions. ${ }^{1}$ In recent years, increasing attention has been paid to elevated levels of CRP as a potential risk factor for atherosclerosis. ${ }^{2}$ An evolving body of epidemiological and laboratory evidence indicates that the screening of CRP levels may be a useful test for predicting the risk of atherosclerotic cardiovascular disease. ${ }^{3}$

Media awareness of CRP as a risk factor is growing as well. A recent cover story on CRP in a widely read periodical, emblazoned with the headline "The Heart Test That Could Save Your Life," further described CRP as an "easy, new way to help predict your risk of heart attack and stroke." ${ }^{4}$ We critically examined the evidence regarding CRP levels as a test for predicting the risk of cardiovascular disease. In particular, we focused on the factors that contribute to the usefulness and validity of any screening test (Table 1). Our evaluation of the literature finds insufficient support for the widespread use of a CRP screening test as a strategy for determining the risk of cardiovascular disease.

The utility of any test depends on its ability to discriminate between individuals who have (or are at risk of) disease and healthy, disease-free individuals. This ability is often expressed in terms of the sensitivity, specificity and predictive values (positive and negative) of the test. ${ }^{5}$ These properties depend on the prevalence of disease in the population being tested and the distribution of competing (similar) conditions. ${ }^{6}$ When applied to populations with a low prevalence of disease, even highly accurate tests may have a poor positive predictive value. Since about $75 \%$ of the adult population is at low to moderate risk of cardiovascular disease, relying solely on any single screening test in isolation (including CRP) will likely generate an excess of false-positive results. ${ }^{7}$

Unfortunately, while a number of studies have indicated that an elevated CRP level confers a higher risk for cardiovascular disease, few studies have reported values for sensitivity and specificity. By extracting data from one such study $^{8}$ and calculating predictive values, Levinson and Elin determined that a CRP concentration in the highest quartile had a positive predictive value of only $0.86 \%$ for the development of cardiovascular disease. ${ }^{9}$ This was due, at least in part, to extensive overlap in the distributions of CRP values between cases and controls.

Another desirable attribute of a screening test for cardiovascular disease risk is the ability to confer predictive value conjointly and incrementally with that of a validated global risk prediction strategy. ${ }^{10}$ In the field of cardiovascular disease prediction, a number of global risk scores are in widespread use, with one of the most validated and timehonoured being the Framingham Risk Score. ${ }^{11}$ Indeed,

\begin{tabular}{|c|c|c|c|}
\hline Characteristic & Data sources & Magnitude of support* & Comments \\
\hline Reliability & Cross-sectional & $\begin{array}{l}\text { Interassay }+++ \\
\text { Within-subject }+ \\
\text { Between-subject + }\end{array}$ & $\begin{array}{l}\text { Multiple determinants of } \\
\text { CRP variability within the } \\
\text { population }\end{array}$ \\
\hline Accuracy & Case-control & $\begin{array}{l}\text { Sensitivity ++ } \\
\text { Specificity }+\end{array}$ & $\begin{array}{l}\text { Few studies report } \\
\text { absolute risk per quartile } \\
\text { or measures of test } \\
\text { performance }\end{array}$ \\
\hline $\begin{array}{l}\text { Additive value (to global risk } \\
\text { scoring) }\end{array}$ & Cohort, case-control & + to ++ & Conflicting data \\
\hline Generalizability & Cohort & $?$ & Limited information \\
\hline Ability to motivate patients & No data & $?$ & Limited information \\
\hline Improved patient outcomes & $\begin{array}{l}\text { Retrospective subgroup } \\
\text { analyses of RCTs }\end{array}$ & ++ & No prospective data \\
\hline
\end{tabular}

Note: $\mathrm{CRP}=\mathrm{C}$-reactive protein, $\mathrm{RCT}=$ randomized controlled trial

$*_{+}=$minimal,$++=$moderate,$+++=$strong, $?=$ unknown. 
global risk scores (such as Framingham) have been incorporated into a number of national treatment guidelines by organizations dedicated to the prevention and treatment of cardiovascular disease. ${ }^{12-14}$

Two studies, with conflicting data, shed light on the ability of the CRP level to provide incremental information to the Framingham Risk Score. ${ }^{15,16}$ The Women's Health Study followed 27939 asymptomatic women for a mean of 8 years to monitor the development of cardiovascular events. ${ }^{15}$ The risk of cardiovascular disease appeared to be modulated by CRP concentration at each level of Framingham-estimated risk. However, as with many other studies of CRP and the risk of cardiovascular disease, only the relative risks of different strata of CRP concentration were provided, making it impossible to predict a given participant's absolute risk of cardiovascular disease.

Conflicting information on the incremental value of CRP is provided by the Rotterdam Study, a populationbased cohort of 7983 men and women aged 55 years and older. ${ }^{16}$ The investigators conducted a nested case-control study comparing 157 participants who had myocardial infarctions during follow-up with 500 randomly selected control subjects. The addition of the CRP level to the Framingham risk function did not improve the area under the receiver operating characteristic curve or increase the sensitivity or specificity of the Framingham risk function. Indeed, the addition of traditional cardiovascular disease risk factors to the univariate analysis relating CRP levels to the risk of infarction substantially attenuated the relation.

Perhaps the ultimate determinant of the usefulness of any screening test is whether patients are better off if the test is used. An effective and valuable screening test for atherosclerosis would safely and inexpensively identify patients at elevated risk of the disease, ideally early in the natural history of the condition (in the presymptomatic phase), affording the opportunity to intervene and prevent the ensuing illness. This is particularly critical in coronary artery disease, where nearly half of initial presenting cases are fatal myocardial infarctions or sudden cardiac death. ${ }^{17}$ Early and widely available screening could therefore have an enormous impact on people with this disease.

In the case of CRP measurement, there is indirect, retrospective evidence that this screening test could be used to target preventive therapy to those at higher risk. Ridker and colleagues conducted a post hoc analysis of the Air Force/Texas Coronary Atherosclerosis Prevention Study, a primary prevention trial of lovastatin in 6605 people with no history of atherosclerotic cardiovascular disease. ${ }^{18}$ The investigators measured baseline CRP levels in 5742 participants. The risk of acute coronary events was related to CRP concentration, with a $17 \%$ increase in adjusted risk with each increasing quartile of CRP $(95 \%$ confidence interval $[\mathrm{CI}] 3 \%-33 \%)$. Moreover, having a CRP level above the study median predicted benefit from lovastatin, irrespective of the low-density lipoprotein cholesterol level. Similar analyses have been reported on the ability of CRP levels to predict benefit from ASA in primary prevention and pravastatin in secondary prevention..$^{19,20}$

However, these studies were retrospective subgroup analyses of trials that were not designed to test a strategy of CRP-guided intervention. The ultimate test for the usefulness of CRP measurement would come from a controlled trial that randomly assigns patients to testing or no testing, directly measuring the harms and benefits of such an approach, with rigorous blinding of both patients and physicians. This strategy could also provide a direct appraisal of the cost-effectiveness of CRP screening in comparison with the use of a validated global risk score, such as the Framingham equation.

The applicability of CRP testing to special populations has not been established. Nearly all studies have been carried out with relatively homogenous white cohorts in North America and Western Europe. Limited data are available for ethnic groups that may be at particularly high risk of cardiovascular disease, such as African, South Asian and Aboriginal populations. Other risk prediction tools such as Framingham have been extrapolated with difficulty to groups beyond their derivation cohort, which has resulted in some misclassification of risk. ${ }^{21-23}$ It is therefore essential that studies of CRP testing take place in these populations before screening can be applied with confidence to all groups.

The evidence base supporting the inclusion of CRP in vascular disease risk assessment is tenuous, incomplete and conflicting. Few studies report critical indices of test validity (e.g., sensitivity, specificity and predictive value); moreover, there are no prospective trials on the issue of whether screening improves patient outcomes. Until these issues are addressed - preferably through rigorous clinical trials employing randomization and blinding - calls for the widespread adoption of CRP measurement as a screening test must be regarded as premature.

This article has been peer reviewed.

From the Institute for Clinical Evaluative Sciences and Division of Clinical Pharmacology and Toxicology (Hackam), and the Division of General Internal Medicine (Shumak), Sunnybrook and Women's College Health Sciences Centre, University of Toronto, Toronto, Ont.

Competing interests: None declared.

\section{References}

1. Ledue TB, Rifai N. Preanalytic and analytic sources of variations in C-reactive protein measurement: implications for cardiovascular disease risk assessment. Clin Chem 2003;49(8):1258-71.

2. Pearson TA, Mensah GA, Alexander RW, Anderson JL, Cannon RO III, Criqui $M$, et al. Markers of inflammation and cardiovascular disease: application to clinical and public health practice. A statement for healthcare professionals from the Centers for Disease Control and Prevention and the American Heart Association. Circulation 2003;107(3):499-511.

3. Danesh J, Whincup P, Walker M, Lennon L, Thomson A, Appleby P, et al Low grade inflammation and coronary heart disease: prospective study and updated meta-analyses. BM7 2000;321(7255):199-204.

4. Comarow A. A message from the heart. US News \& World Report;2002Nov25: $55-6,59-60,62$

5. Feinstein AR. Clinical biostatistics XXXI. On the sensitivity, specificity, and discrimination of diagnostic tests. Clin Pharmacol Ther 1975;17(1):104-16.

6. Jaeschke R, Guyatt G, Sackett DL. Users' guides to the medical literature. 
III. How to use an article about a diagnostic test. A. Are the results of the study valid? Evidence-Based Medicine Working Group. 7AMA 1994;271(5):389-91.

7. Jacobson TA, Griffiths GG, Varas C, Gause D, Sung JC, Ballantyne CM. Impact of evidence-based "clinical judgment" on the number of American adults requiring lipid-lowering therapy based on updated NHANES III data. National Health and Nutrition Examination Survey. Arch Intern Med 2000;160 (9):1361-9.

8. Ridker PM, Hennekens CH, Buring JE, Rifai N. C-reactive protein and other markers of inflammation in the prediction of cardiovascular disease in women. N Engl 7 Med 2000;342(12):836-43.

9. Levinson SS, Elin RJ. What is C-reactive protein telling us about coronary artery disease? Arch Intern Med 2002;162(4):389-92.

10. Hackam DG, Anand SS. Emerging risk factors for atherosclerotic vascular disease: a critical review of the evidence. $7 A M A$ 2003;290(7):932-40.

11. Wilson PW, D'Agostino RB, Levy D, Belanger AM, Silbershatz H, Kannel WB. Prediction of coronary heart disease using risk factor categories. Circulation 1998;97(18):1837-47.

12. The sixth report of the Joint National Committee on prevention, detection, evaluation, and treatment of high blood pressure. Arch Intern Med 1997;157 (21):2413-46

13. Executive Summary of the third report of the National Cholesterol Education Program (NCEP) Expert Panel on Detection, Evaluation, and Treatment of High Blood Cholesterol in Adults (Adult Treatment Panel III). FAMA 2001; 285(19):2486-97.

14. Wood D, De Backer G, Faergeman O, Graham I, Mancia G, Pyorala K. Prevention of coronary heart disease in clinical practice. Summary of recommendations of the Second Joint Task Force of European and other Societies on Coronary Prevention. 7 Hypertens 1998;16(10):1407-14.

15. Ridker PM, Rifai N, Rose L, Buring JE, Cook NR. Comparison of C-reactive protein and low-density lipoprotein cholesterol levels in the prediction of first cardiovascular events. N Engl f Med 2002;347(20):1557-65.

16. Van der Meer I, de Maat MP, Kiliaan AJ, van der Kuip DA, Hofman A, Wit- teman JC. The value of C-reactive protein in cardiovascular risk prediction: the Rotterdam Study. Arch Intern Med 2003;163(11):1323-8.

17. American Heart Association. 2002 Heart and Stroke statistical update. Available: www.americanheart.org/presenter.jhtml?identifier=3000093 (accessed 2004 Mar 9).

18. Ridker PM, Rifai N, Clearfield M, Downs JR, Weis SE, Miles JS, et al. Measurement of C-reactive protein for the targeting of statin therapy in the primary prevention of acute coronary events. N Engl 7 Med 2001;344(26):195965.

19. Ridker PM, Rifai N, Pfeffer MA, Sacks FM, Moye LA, Goldman S, et al. Inflammation, pravastatin, and the risk of coronary events after myocardial infarction in patients with average cholesterol levels. Cholesterol and Recurrent Events (CARE) Investigators. Circulation 1998;98(9):839-44.

20. Ridker PM, Cushman M, Stampfer MJ, Tracy RP, Hennekens CH. Inflammation, aspirin, and the risk of cardiovascular disease in apparently healthy men. N Engl 7 Med 1997;336(14):973-9.

21. D'Agostino RB Sr, Grundy S, Sullivan LM, Wilson P; CHD Risk Prediction Group. Validation of the Framingham Coronary Heart Disease Prediction Scores: results of a multiple ethnic groups investigation. $7 A M A 2001 ; 286(2)$ $180-7$.

22. Quirke TP, Gill PS, Mant JW, Allan TF. The applicability of the Framingham coronary heart disease prediction function to black and minority ethnic groups in the UK. Heart 2003;89(7):785-6.

23. Ramachandran S, French JM, Vanderpump MPJ, Croft P, Neary RH. Using the Framingham model to predict heart disease in the United Kingdom: retrospective study. BM7 2000;320(7236):676-7.

Correspondence to: Daniel G. Hackam, Rm. E-242, Sunnybrook and Women's College Health Sciences Centre, 2075 Bayview

Ave., Toronto ON M4N 3M5; fax 416 480-4563;

danhackam@rogers.com

\title{
How you can get involved in the CMA!
}

The CMA is committed to providing leadership for physicians and promoting the highest standard of health and health care for Canadians. To strengthen the Association and be truly representative of all Canadian physicians, the CMA needs to hear from members interested in serving in elected positions and on appointed committees and advisory groups.

The CMA structure comprises both governing bodies and advisory bodies either elected by General Council or appointed by the CMA Board of Directors. The Board of Directors — elected by General Council — has divisional, affiliate, resident and student representation, is responsible for the overall operation of the CMA and reports to General Council on issues of governance. CMA councils and committees advise the Board of Directors and make recommendations on specific issues of concern to physicians and the public. Four core councils and committees consist of either divisional or regional representation, while other statutory and special committees, and expert working and project advisory groups comprise individuals with interest and expertise in subject-specific fields. Positions on one or more of these committees may become available in the coming year.

For further information on how you can get involved, please contact:

\author{
Prunella Hickson \\ Corporate Affairs \\ Canadian Medical Association \\ 1867 Alta Vista Drive \\ Ottawa ON K1G 3 Y6 \\ Fax 613 526-7570 \\ Tel $1800663-7336$, x2249 \\ Email prunella.hickson@cma.ca
}

By getting involved, you will have an opportunity to make a difference.

We hope to hear from you. 